\title{
Barrier properties of corn zein nanocomposite coated polypropylene films for food packaging applications
}

\author{
Onur Ozcalik ${ }^{\mathrm{a}}$, Funda Tihminlioglu ${ }^{\mathrm{b}, *}$ \\ a İzmir Institute of Technology, Materials Science and Engineering Program, 35430 Gülbahçe-Urla, İzmir, Turkey \\ b Izmir Institute of Technology, Chemical Engineering Department, 35430 Gülbahçe-Urla, İzmir, Turkey
}

\section{A R T I C L E I N F O}

\section{Article history:}

Received 22 July 2011

Received in revised form 6 April 2012

Accepted 8 September 2012

Available online 21 September 2012

\section{Keywords:}

Polypropylene

Corn zein

Biopolymer

Nanocomposite coating

Barrier properties

\begin{abstract}
A B S T R A C T
The feasibility of corn zein nanocomposite (CZNC) coatings as an alternative to synthetic polymer barrier layer on polypropylene (PP) films was examined. The effect of layered silicate content in the CZNC layers on the barrier and surface hydrophobicity of the CZNC-PP films were investigated. Incorporation of organomodified montmorillonite (OMMT) by solution intercalation into zein matrix significantly improved oxygen and water vapor barrier of coated PP films. The barrier properties were also investigated theoretically by using various phenomenological permeability models. Tortuous permeation path formed by the fine delamination of nanoclays was found to be responsible for the barrier improvements in zein layers. In conclusion, durable CZNC-PP laminates were developed. CZNC coating of PP films has reduced the oxygen permeability nearly four times, while water vapor permeability reduced by $30 \%$ with $5 \mathrm{wt} . \%$ OMMT content in $5.9 \mu \mathrm{m}$ corn zein coating.
\end{abstract}

(ㄷ) 2012 Elsevier Ltd. All rights reserved.

\section{Introduction}

Food packaging deals with the preservation of food quality during the period from its production to its end use. Today, synthetic polymers are the main packaging materials since they offer versatile solutions for several needs of food packaging. Conventional packaging polymers are begun to be questioned due to increasing environmental concerns and their petroleum based sources. Research on sustainable alternative materials for food packaging is a hot topic for over a decade. Biopolymers are drawing attention of many researchers especially because of their petroleum independent sources and eco-friendliness. Most of biopolymers are synthesized from microorganisms or extracted directly from biomass. Biopolymers with their annual totally renewable sources and incomparably shorter degradation times can be utilized for sustainable packaging (Cutter, 2006).

Protein based biopolymers such as corn zein, soy or whey proteins extracted from byproducts of food industry have desirable properties such as biodegradability and strong barrier to oxygen for food packaging. The most important feature of protein based biopolymers is their excellent barrier to oxygen, comparable to that of ethylene vinyl alcohol $(\mathrm{EVOH})$ or polyvinylidine chloride (PVDC) (Miller and Krochta, 1997; Padua and Wang, 2002).

Particularly among proteins, corn zein; obtained from the corn gluten that is a byproduct of corn wet milling industry; has great

\footnotetext{
* Corresponding author. Tel.: +90 232750 6651; fax: +90 2327506645 .

E-mail address: fundatihminlioglu@iyte.edu.tr (F. Tihminlioglu).
}

potential to be used in food packaging applications. Protein based polymers are heterogeneous polymers, owing their functionality to amino acids in their structures (Shukla and Cheryan, 2001; Lawton, 2002). Proteins are mostly hydrophilic, being very sensitive to humidity and mostly soluble in water constituting for an important limitation for their use in food packaging applications. On the contrary, zein is not soluble in water although its properties are still being dependent on relative humidity. Corn zein is relatively hydrophobic due to its high content of non-polar amino acids (Gioia and Guilbert, 1999; Padua and Wang, 2002). Being a better barrier to moisture compared to other proteins and an excellent barrier to oxygen, use of corn zein standalone films in food packaging applications seem impossible with current status due to poor mechanical properties. In addition to use of various plasticizers in order to increase flexibility of films (Gioia and Guilbert, 1999; Lawton, 2004; Hernandez-Izquerdo and Krochta, 2008), many hybrid strategies were developed to put corn zein in use in order to utilize its sustainability and excellent barrier to oxygen. These include lamination of zein with other proteins and lipids (Weller et al., 1998; Cho et al., 2002; Ryu et al., 2002; Ghanbarzadeh and Oromiehi, 2008), blending with synthetic polymers or biopolymers (Herald et al., 2002; Wu et al., 2003; Corradini et al., 2004) and coating polyolefin surfaces with corn zein (Lee et al., 2008; Tihminlioglu et al., 2010, 2011). Biopolymer coatings such as corn zein may be beneficial in environmental aspect, since identification and separation of layers for recycling of synthetic films are problematic and multilayer structures used for barrier applications constitute for an important amount of waste (Cutter, 2006; Marsh and Bugusu, 2007). 
In this study, feasibility of further improvements in layered silicate loaded biopolymer coatings on commercial polypropylene films were investigated. Layered silicate nanocomposites (LSNC), were successfully used to improve properties of synthetic polymers and are currently being put in use by food packaging industry (Lange and Wyser, 2003). Unique improvements brought in by clay nanoplatelets intercalated or exfoliated within the polymer matrix were well reviewed in the literature (Alexandre and Dubois, 2000; Ray and Bousmina, 2005; Paul and Robeson, 2008; Pavlidou and Papaspyrides, 2008; Herrera-Alonso et al, 2009). Improved elastic modulus and tensile strength at break due to strong interactions between high surface area LS and polymer matrix and improvements in barrier properties due to enhanced tortuosity (Petersson and Oksman, 2006; Paul and Robeson, 2008; Pavlidou and Papaspyrides, 2008; Choudalakis and Gotsis, 2009) are promising features of biopolymer nanocomposites in food packaging aspect.

Incorporation of filler materials in order to improve the barrier of polymers is a well known technique in food packaging applications. LSNC applications are attractive in this field since high aspect ratio and geometry of LS enables unique improvements without trading off the mechanical properties. The same level of barrier improvement can be achieved by small LS nanoclay content without diminishing the mechanical performance of polymeric materials. Moreover, many studies showed adjoined mechanical property improvements in LSNC applications (Ray and Bousmina, 2008; Tunc et al., 2007; Bae et al., 2009).

Therefore, the primary objective of this study was to develop a corn zein nanocomposite (CZNC) coated polypropylene (PP) film structure and investigate the effect of coatings on oxygen and water vapor permeability of the films. The effect of nanoclay content and organomodification of layered silicates on the permeability data was also investigated.

\section{Materials and methods}

\subsection{Materials}

Corn zein used in this study was obtained from Sigma-Aldrich. Ethanol (lab-grade, >99.5\%) used as solvent for zein was supplied from Panreac. Dilution of lab-grade ethanol to $95 \%$ (v/v) was done with ultra pure water. Nanocomposites were prepared by using the commercial organomodified layered silicate nanoclays, Cloisite 10A (125 meq/100 g clay) obtained from Southern Clay - Rockwood. Glycerol ( $\mathrm{Mw}=92 \mathrm{~g} / \mathrm{mol}$ ) was used as plasticizer to increase the elasticity of corn zein layers was obtained from Fluka. Plasticized corn zein nanocomposites were casted on commercial corona treated $40 \mu \mathrm{m}$ thickness polypropylene $(\mathrm{C} 11 / 40 \mu \mathrm{m})$ films, supplied by Polinas Company (Manisa/Turkey).

\subsection{Preparation of CZNC-PP samples}

Corn zein nanocomposite coating was prepared by solution intercalation method. Different amounts of commercial organomodified nanoclay (see Table 1) were first dispersed in $50 \mathrm{ml}$ of aqueous $(95 \% \mathrm{v} / \mathrm{v})$ ethanol by stirring. Then, in order to open clay stackings, stirred solution was sonicated for $60 \mathrm{~min}$ by using an ultrasonic processor (Sonix Vibracell 505) type probe sonicator working at $40 \%$ capacity of its $20 \pm 0.05 \mathrm{kHz}$ output. Corn zein $(5 \% \mathrm{w} / \mathrm{v}$ ethanol) was dissolved within the clay dispersion. After complete dissolution of zein, $20 \% \mathrm{w} / \mathrm{w}$ glycerol was then added to plasticize the CZNC :corn zein nanocomposite and the second sonication step was applied for $60 \mathrm{~min}$ in order to obtain further entering of plasticized biopolymer chains inside clay platelets. Sonication steps were done in a cooling water bath in order to prevent degradation of corn zein at high temperatures. The prepared CZNC
Table 1

The measured thicknesses of CZNC coated PP films and single CZNC coatings according to OMMT content.

\begin{tabular}{lcc}
\hline Sample code & Coated film thickness $(\mu \mathrm{m})$ & Coating thickness $(\mu \mathrm{m})$ \\
\hline PP & 40 & \\
PPZ & $46 \pm 0.89$ & $6 \pm 0.89$ \\
CLO10A-1\% & $46.8 \pm 1.17$ & $6.8 \pm 1.17$ \\
CLO10A-3\% & $46.8 \pm 0.75$ & $6.7 \pm 0.75$ \\
CLO10A-5\% & $45.9 \pm 0.66$ & $5.9 \pm 0.66$ \\
CLO10A-7.5\% & $47.6 \pm 0.80$ & $7.6 \pm 0.80$ \\
\hline
\end{tabular}

solution was immediately casted on corona discharged commercial polypropylene (PP) films with $40 \mu \mathrm{m}$ thickness (C11/40) obtained from the Polinas Company (Manisa, Turkey) with a custom blade by using automatic constant speed film applicator (Sheen $1133 \mathrm{~N}$ ). Then, the prepared CZNC coated polypropylene films were first put into a vacuum oven overnight in order to achieve complete evaporation of solvent at $120^{\circ} \mathrm{C}$. All films were kept in desiccator to prevent films absorb water vapor from atmosphere until testing.

\subsection{Determination of film thickness}

Thicknesses of prepared CZNC-PP films 155 with various clay contents were measured with an electronic digital micrometer (Mitutoyo, 293-821) with $0.001 \mathrm{~mm}$ sensitivity. The thicknesses used for permeability analysis evaluations were determined by taking at least five different measurements from random sections of films. Thicknesses of individual CZNC layers used in oxygen and water vapor permeability calculations were determined by subtracting the thickness of polypropylene thickness $(40 \mu \mathrm{m})$ from the measured total thickness.

\subsection{XRD analysis of CZNC-PP samples}

X-ray diffraction (XRD) analysis of CZNC coated PP films were conducted by using Philips X'Pert Pro MRD with $\mathrm{Cu} \mathrm{K} \alpha$ radiation $(\lambda=1.542 \mathrm{~nm})$ under a voltage of $40 \mathrm{kV}$ and a current of $40 \mathrm{~mA}$. The analysis were conducted from CZNC coated side of the films and no peak belonging to corn zein or PP was observed in the scanned diffraction angles between $2 \theta=1.7-8^{\circ}$ for samples prepared by using organomodified nanoclays.

Basal spacings of layered silicates in the corn zein matrix were calculated by using Bragg's Law (Eq. (1)), where $\lambda$ corresponds to the wavelength of the X-ray source used, $\theta$ is the diffraction angle measured and $d$ is the spacing between diffractional lattice planes

$\lambda=2 d \sin \theta$

\subsection{FTIR analysis of CZNC-PP samples}

Infrared spectra of the prepared films were obtained by using a FTIR-ATR spectrometer (Perkin Elmer Spectrum 100). Film spectra were collected with a resolution of $4 \mathrm{~cm}^{-1}$ and averaging 64 scans by using ZnSe crystal and DTGS detector in the $4000-650 \mathrm{~cm}^{-1}$ wave number range. Spectra of Cloisite 10A OMMT and analysis of prepared films below $650 \mathrm{~cm}^{-1}$ wave numbers were obtained by using a FTIR spectrometer (Shimadzu FTIR 8201) by averaging 64 scans with a resolution of $4 \mathrm{~cm}^{-1}$.

\subsection{Oxygen permeability analysis of CZNC-PP samples}

Oxygen permeability (OP) of CZNC coated PP film samples was determined by using gas permeation instrument, (Dansensor Lyssy, L-100-5000 Manometric Gas permeability Tester) according 
to ASTM 3985 standard. OP measurements were conducted at $23{ }^{\circ} \mathrm{C}$ and $0 \% \mathrm{RH}$ by placing PP surface of the multilayer films to the oxygen rich side. All films were analyzed for three different samples and averages together with standard deviations were reported as the oxygen permeability data.

Permeability of single CZNC layers was calculated 183 from the CZNC-PP results, using the multilayer permeability equation:

$\frac{L}{P}=\sum_{i=1}^{n} \frac{L_{i}}{P_{i}}$

where $n$ is the number of layers, $L$ and $P$ are the thickness and permeability of the multilayer film, $L_{i}$ and $P_{i}$ is the thickness and permeability of each layer, respectively.

\subsection{Water vapor permeability analysis of CZNC-PP samples}

Mocon Permatran 3/33 water vapor permeability analyzer was used to investigate the effect of nanocomposite coating layer on water vapor permeability (WVP) of CZNC coated PP films. All WVP tests were conducted at $37.8{ }^{\circ} \mathrm{C}$ and $90 \% \mathrm{RH}$ according to ASTM F1249 standard. All films were analyzed for three different samples and averages together with standard deviations were reported as the water vapor permeability data. The test film was placed between two test cells where PP surface of the film was in the water vapor rich side. Carrier gas, nitrogen, was passed through ultra pure water to adjust the $\mathrm{RH}$ and flowed into the test cell. As the water vapor diffused through the test film, it was carried by nitrogen to the detector. Nitrogen flow rate was set to $100 \mathrm{~cm}^{3}$ per minute. The data were recorded as water vapor transmission rate (WVTR). Permeability of the samples was calculated by using the Eq. (3):

Permeability $=\frac{\text { WVTR }}{S\left(R_{1}-R_{2}\right)} * L_{f i l m}$

where, $R_{1}$ is relative humidity at the source expressed as a fraction ( $R_{1}=0.9$ for $90 \% \mathrm{RH}$ chamber), $R_{2}$ is relative humidity of the vapor sink expressed as a fraction $\left(R_{2}=0\right.$ for the $0 \%$ RH chamber (dry side)), $S$ is the vapor pressure of water at the test temperature and $L_{\text {film }}$ is the thickness of the tested film. Three different samples for each formulation were tested and their average was reported. WVP of single CZNC layers were calculated by using the multilayer permeability equation (Eq. (2)).

\subsection{Contact angle measurements of CZNC-PP samples}

Initial contact angle of water in air on the CZNC-209 PP surfaces was measured with a contact angle analyzer (Attension Theta Optical Tensiometer, KSV Instruments) by dropping a constant $6 \mu \mathrm{l}$ of water onto the CZNC surface of the films by using an automatic micro syringe. Distilled water was used as a probe liquid. An image of water drop was recorded immediately just after dropping from the syringe and the contact angle of water drop analyzed digitally by using the software of the device. A total of seven samples were tested each sample film and averages together with standard deviations were reported.

\section{Results and discussion}

Corn zein nanocomposites (CZNCs) were prepared by solution intercalation method by using commercial organically modified layered silicate nanoclay Cloisite 10A (OMMT). The prepared films were named according to their clay content as CLO10A-1\% to CLO10A-7.5\% as seen in Table 1; while PP and PPZ were used for the commercial polypropylene film and plasticized corn zein coated PP films without nanoclays, respectively. Prepared CZNC solutions were successfully coated onto films since substrate PP was a corona treated film for good adhesion of zein coatings. Corn zein is inherently yellow color and nanoclay addition into polymer matrix may deteriorate the color properties of polymers. Meanwhile, in this study no color change that may be detected by human eye was detected for the CZNC coatings prepared by Cloisite $10 \mathrm{~A}$ nanoclays by taking base PP film as reference. Color changes of CZNC coatings are discussed elsewhere (Ozcalik, 2010).

\subsection{Structural characterization of corn zein nanocomposite coating layer}

The level of layered silicate delamination in the matrix is a critical issue for polymer nanocomposites. Effective delamination and dispersion of nanofillers allows utilization of enormous surface area of layered silicates available for bonding with the polymer matrix. Structural characterizations of corn zein nanocomposite coated polypropylene films were done in order to understand the effect of CZNC structure on the performance of films. Characterization of nanocomposite structure of the CZNC layers were done by using X-ray diffraction (XRD) and Fourier transform infrared (FTIR) analysis.

\subsubsection{XRD analysis}

Assessment of the layered silicate nanoclay delamination in the corn zein matrix was done by XRD analysis. XRD allows interpretation of nanocomposite structure depending on the shape, intensity and position of $\langle 001\rangle$ diffraction of layered silicates. Peak shifts to lower angles and/or broader peaks are attributed to intercalated or exfoliated structures depending on the level of changes in the XRD chromatograms.

$\langle 001\rangle$ diffraction of organomodified Cloisite $10 \mathrm{~A}$ nanoclay powder was obtained at $4.65^{\circ}$ (Fig. 1) indicating a calculated basal spacing of 19.02 Å by Bragg's Law (Eq. (1)). Position of characteristic Cloisite 10 A peak was in agreement with the value (19.2 A) reported by the supplier. XRD analysis was suitable to assess nanocomposite structure of CZNC layers, since substrate PP films and corn zein matrix of coating layer gave no reflection in the analyzed range. XRD results of corn zein coated PP film and CZNC-PP films, prepared by incorporating Cloisite $10 \mathrm{~A}$ in zein coating layers, were given together in Fig. 1.

Complete disappearance of $\langle 001\rangle$ reflection of organomodified Cloisite 10A nanoclay for CLO10A-3\% CZNC-PP sample can be attributed to enhanced intercalation of layered silicates. According to XRD results; up to $3 \mathrm{wt}$.\% nanoclay content, distances between

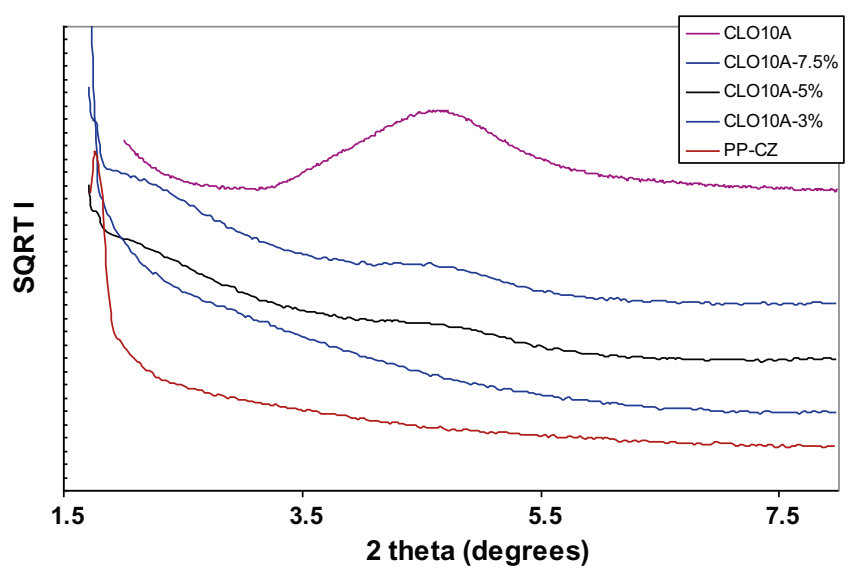

Fig. 1. XRD chromatogram of CZNC-PP films prepared by incorporation of OMMT in the coating layer, sample codes given in legend denotes order of samples in the figure. 
LS platelets increased to more than $51.9 \AA$ from $19.02 \AA$ after sonication, falling behind the detection limit of XRD. Such increase between nanoclay platelets that lead to disappearance of characteristic peak can be taken as an indication of possible exfoliation of nanoclay platelets in the corn zein matrix. Nanoclay stacks wide open and platelets disperse disorderly in several directions diminishing the XRD reflection in exfoliated nanocomposite structures (Alexandre and Dubois, 2000; Ray and Bousmina, 2005). Meanwhile, further TEM analyses are required to assert an exfoliated nanocomposite structure in CLO10A-3\% samples.

Characteristic diffraction of Cloisite $10 \mathrm{~A}$ nanoclay at $4.65^{\circ}$ becomes slightly visible for CLO10A-5\% sample and more significant for CLO10A-7.5\% sample. Appearance of broad characteristic peak can be attributed to decreased delamination of nanoplatelets with increasing nanoclay loading. Meanwhile, considering the slightbroad diffraction at $1.97^{\circ}$ for CLO10A-5\% coating and $2.25 \theta$ for CLO10A-7.5\% coating (Fig. 1), it can be claimed that nanocomposite structure turns into more intercalated structure with lower stack openings due to increased amount of nanoclays present in the corn zein matrix. Though nanocomposite structure began to turn more intercalated, the interlayer spacing of nanoplatelets are still higher than that of pristine Cloisite 10A powder.

\subsubsection{FTIR analysis}

FTIR analysis can be used to identify structural changes occurred due to exfoliation/intercalation of layered silicates in the polymer matrix. Better dispersion of layered silicate nanoplatelets are expected to give rise to the available number of bonding sites with the matrix. Besides, new bonds between nanoclays and matrix may occur. FTIR-ATR was used in combination with FTIR in order to observe the effects of nanocomposite development on zein structure without dealing with intensities of the peaks and detailed quantitative investigations. Qualitative FTIR discussions were done in $850-1150 \mathrm{~cm}^{-1}$ (Fig. 2), and in $1450-1800 \mathrm{~cm}^{-1}$ regions where significant changes were observed (Fig. 3). Positions and assignments of FTIR bands of CZNC-PP films were given in Table 2.

The most distinctive changes in FTIR spectra can be observed in $850-1150 \mathrm{~cm}^{-1}$ region. Originally, OMMT (Cloisite $10 \mathrm{~A}$ ) has a broad band at $750-1350 \mathrm{~cm}^{-1}$ region. While pristine corn zein does not give any band in this region, incorporation of Cloisite $10 \mathrm{~A}$ into the zein matrix resulted in significant changes in the FTIR spectra.

Small concentration of clay leads to arise of a small band at around wave number of $1040 \mathrm{~cm}^{-1}$, that is generally assigned to in-plane $\mathrm{Si}-\mathrm{O}$ bands (oriented parallel to clay layer) (Chen et al.,

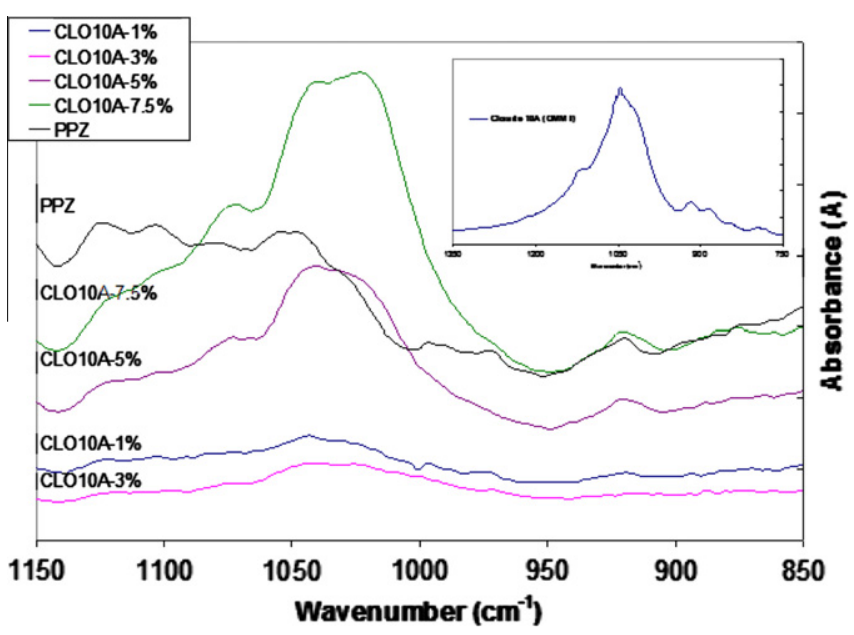

Fig. 2. FTIR-ATR spectra of prepared CZNC-PP films in $850-1150$ wavenumber region.

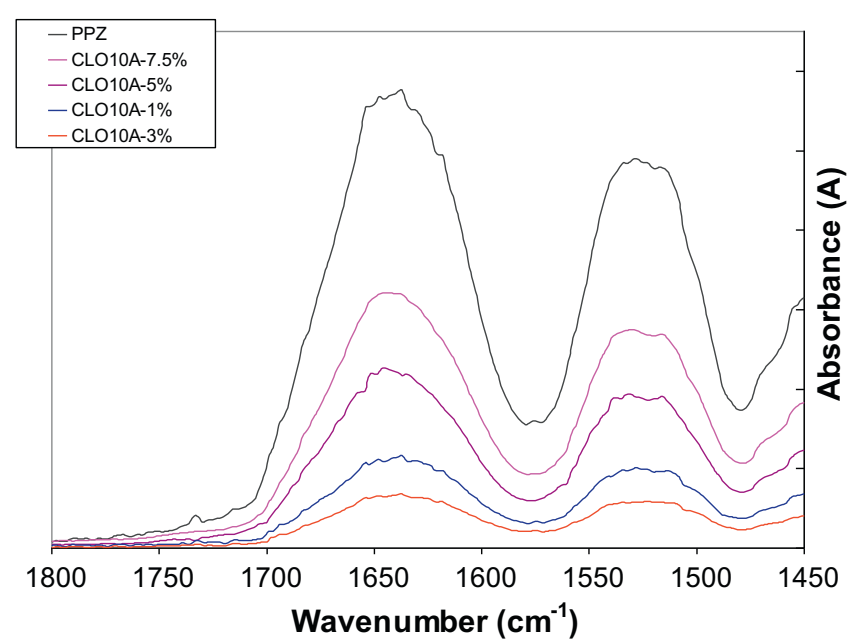

Fig. 3. FTIR-ATR spectra of prepared CZNC-PP films in 1450-1800 wavenumber region, sample codes given in legend denotes order of samples in the figure.

Table 2

Positions and assignments of characteristic bands of CZNC-PP films, corn zein and Cloisite 10A OMMT.

\begin{tabular}{|c|c|c|}
\hline Sample & Wavenumber $\left(\mathrm{cm}^{-1}\right)$ & Assignment \\
\hline \multicolumn{3}{|l|}{ Cloisite 10A } \\
\hline \multirow{6}{*}{$\mathrm{Si}-\mathrm{O}-\mathrm{Si}$ bands } & 1040 & In-plane Si-O stretching \\
\hline & 1122 & In-plane $\mathrm{Si}-\mathrm{O}$ stretching \\
\hline & 1023.43 & In-plane $\mathrm{Si}-\mathrm{O}$ stretching \\
\hline & 1072 & Out-of-plane $\mathrm{Si}-\mathrm{O}$ stretching \\
\hline & 522.73 & Al-O stretching \\
\hline & 462.93 & Si-O bending \\
\hline \multicolumn{3}{|l|}{ Corn zein } \\
\hline & $1637.49-1645.57$ & Amide I region ( $\mathrm{C}=\mathrm{O}$ stretching) \\
\hline & $1528.47-1531$ & $\begin{array}{l}\text { Amide II region }(\mathrm{N}-\mathrm{H} \text { bending } \\
\text { and } \mathrm{C}-\mathrm{N} \text { stretching) }\end{array}$ \\
\hline
\end{tabular}

2001; Ijdo et al., 2006; Yu et al., 2007). Layered silicates, in their clay agglomerate form, gives a large band in the region 750$1350 \mathrm{~cm}^{-1}$ consisting of several $\mathrm{Si}-\mathrm{O}-\mathrm{Si}$ bands overlapping each other depending on the clay type (montmorillonite, kaolinite etc.) (Johnston and Premachandra, 2001; Madejova, 2003; Cervantes-Uc et al., 2007). Opening of layered silicate galleries leads to appearance of new $\mathrm{Si}-\mathrm{O}$ bands (Johnston and Premachandra, 2001; Ijdo et al., 2006). Existence of several Si-O bands can be more easily seen in CLO10A-5\% spectra in Fig. 2, due to an increase in clay content. Another in plane $\mathrm{Si}-\mathrm{O}$ band at $1122 \mathrm{~cm}^{-1}$ was detected which was observed as a small shoulder for original clay powder as seen in the inset of Fig. 2. A new band at $1023.43 \mathrm{~cm}^{-1}$ was observed in CLO10A-7.5\% coating additional to peak at $1040 \mathrm{~cm}^{-1}$ which should be attributed to a new Si related bond due to changing structure with increasing Cloisite $10 \mathrm{~A}$ nanoclay content.

Powder FTIR patterns of packed layered silicate platelets only gave in-plane $\mathrm{Si}-\mathrm{O}$ bands overlapping each other. Different than the powder pattern, in the FTIR-ATR spectra of nanocomposite coatings a new band appeared at wave number of $1072 \mathrm{~cm}^{-1}$ as seen in Fig. 2. The new occurring band was assigned to out-ofplane $\mathrm{Si}-\mathrm{O}$ bonding (normal to clay layer). Several nanocomposite studies showed appearance of such bands due to opening of clay galleries and dispersion of clay platelets. Ijdo and coworkers studied organoclay delamination in solutions and in LDPE nanocomposites using FTIR-ATR in their study. Besides appearance of new out-of-plane band, research group also reported bandwidth narrowing in $850-1150 \mathrm{~cm}^{-1}$ region due to transition to more exfoliated state for several layered silicate solutions and nanocomposites 
(Ijdo et al., 2006). CZNC coatings prepared by Cloisite 10A showed narrower bands for smaller clay contents, as very slight bands for CLO10A-1\% and CLO10A-3\% samples in the $850-1150 \mathrm{~cm}^{-1}$ region (Fig. 2). In addition to discussed new bands at $850-1150 \mathrm{~cm}^{-1}$ region, two new organomodified nanoclay bands were appeared in the FTIR spectra of CZNC coatings at $522.73 \mathrm{~cm}^{-1}$ and $462.93 \mathrm{~cm}^{-1}$ wave numbers assigned to $\mathrm{Al}-\mathrm{O}$ stretching and $\mathrm{Si}-\mathrm{O}$ bending (Chen et al., 2001). Similar to OMMT bands of 850 $1150 \mathrm{~cm}^{-1}$ region, FTIR bands of $\mathrm{Al}-\mathrm{O}$ and $\mathrm{Si}-\mathrm{O}$ were observed to become broader with increasing organomodified nanoclay content.

Significant bands at 1528.47 and $1637.49 \mathrm{~cm}^{-1}$ in FTIR-ATR spectra given in Fig. 3 were attributed to Amide II and Amide I bands of corn zein, respectively. While Amide II region of nanocomposites showed wave number shift to $1531 \mathrm{~cm}^{-1}$ in CLO10A5\% sample and no change for CLO10A-7.5\%; effect of nanoclay was more significant in Amide I. Although position of Amide II bands of CLO10A-1\% and CLO10A-3\% did not change significantly as seen in Fig. 3, several smaller bands appeared that were attributed to exfoliation of organomodified nanoclays in corn zein matrix. Effect and degree of delamination can be more significantly followed in higher clay content CZNC coatings. Amide I band of corn zein shifted to higher wave numbers; 1643.05 and $1645.57 \mathrm{~cm}^{-1}$ in CLO10A-7.5\% and CLO10A-5\% coatings, respectively. Shifting of Amide I to higher wavelength is attributed to increased hydrogen bonding (Madejova, 2003; Gao et al., 2006). As OMMT dispersion increases, more bonding sites on OMMT gallery will be able to form new hydrogen bonds. $\mathrm{C}=\mathrm{O}$ containing molecules of protein based biopolymers are able to form hydrogen bonding with the $\mathrm{Si}-\mathrm{O}-\mathrm{Si}$ and $-\mathrm{OH}$ containing galleries of OMMT particles resulting in shifting of Amide bands (Chen and Zhang, 2006; Yu et al., 2007). Considering the more explicit XRD diffraction data of CLO10A-7.5\% sample together with FTIR data; shift from 1645.57 to $1643.05 \mathrm{~cm}^{-1}$ with increasing OMMT content can be attributed to poorer dispersion of nanoclay platelets within the zein matrix in the sample.

\subsection{Barrier properties of corn zein nanocomposite coated films}

This section deals with the evaluation of oxygen and water vapor properties of prepared CZNC-PP coatings. The effect of nanoclay content and nanoclay organomodification on the barrier properties of both corn zein nanocomposite coating layer and CZNC-PP bilayer films was studied.

\subsubsection{Oxygen barrier properties}

Oxygen barrier performances of prepared coatings were analyzed at $23{ }^{\circ} \mathrm{C}$ and $0 \% \mathrm{RH}$. Oxygen barrier improvements obtained by the CZNC coatings on PP substrates were reported as a function of nanoclay concentration in Fig. 4. Corn zein and other plant based protein polymers are excellent oxygen barriers due to the presence of polar interactions in their structure (Padua and Wang, 2002; Tharanathan, 2003; Hong and Krochta, 2003, 2006; Rhim et al., 2006). As seen in the Fig. 4, a thin layer of corn zein layer without nanoclays coated on substrate film resulted in 56\% decrease for oxygen molecules permeating through the film. Such result was expected since oxygen permeability of corn zein is far lower than polyolefins such as PP and PE; being comparable to well known oxygen barriers EVOH and PVDC (Padua and Wang, 2002; Cuq et al., 1998; Miller and Krochta, 1997; Tihminlioglu et al., 2010). Oxygen transmission of single corn zein layer was calculated as $131.89 \mathrm{ml} / \mathrm{m}^{2}$ day; 12 -fold lower than that of PP film $\left(1627.85 \mathrm{ml} / \mathrm{m}^{2}\right.$ day); being in good accordance with literature data. Conformably to the prepared CZNC-PP films, several studies showed significant decreases in oxygen permeability with corn zein (Tihminlioglu et al., 2010) and whey protein isolate (Hong and Krochta, 2003, 2006) coatings on PP and PE films. Further

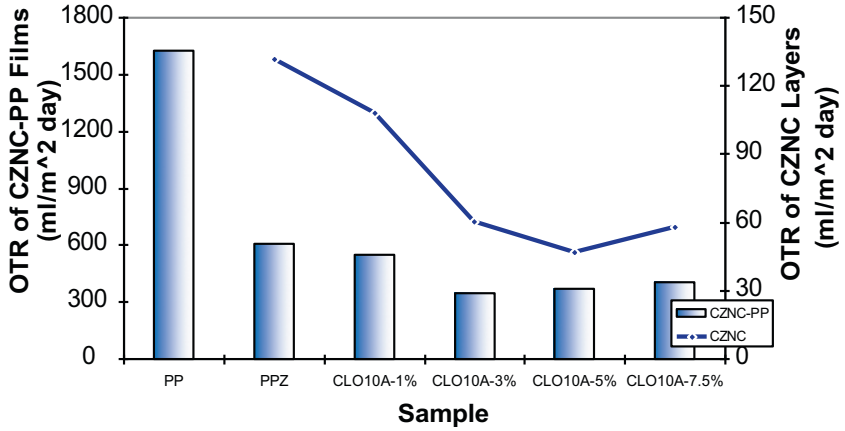

Fig. 4. Oxygen transmission rates (OTR) values of CZNC-PP films (in columns - left $y$-axis) and single CZNC layers (curve - right $y$-axis).

improvement in oxygen barrier was also observed by the CZNC coatings on PP as seen in Fig. 4. Nanocomposite coatings prepared with 3 and $5 \mathrm{wt} . \%$ organomodified nanoclay with respect to dry corn zein decreased oxygen permeation to $25 \%$ of the base PP film. Since no nanocomposite structure exists in substrate films, it is obligatory to follow the effect of nanofiller incorporation on oxygen permeability for single CZNC layers. Oxygen permeation of CZNC layers were evaluated by using the multilayer layer model (Eq. (2)) given in experimental section and plotted together with CZNC-PP film permeation results in Fig. 4. As evidenced from Fig. 4, nanocomposites prepared by small concentrations of Cloisite $10 \mathrm{~A}$ have significant effect on oxygen permeability of corn zein. Continuous decrease in oxygen permeation was observed with increasing clay content, and oxygen permeability of CZNC layer decreased by 56\% and 65\% for CLO10A-3\% and CLO10A-5\% samples, respectively (Fig. 4). Increased oxygen barrier of the CZNC layers can be interpreted as a result of layered silicate exfoliation in the corn zein matrix. Improved barrier of LSNC systems could be mainly attributed to the formation of more tortuous path developed by the well dispersed (partial or totally exfoliated) nanoclay platelets within the polymer matrix (Paul and Robeson, 2008; Choudalakis and Gotsis, 2009; Bae et al., 2009; Luecha et al., 2010). Impermeable layered silicate platelets interrupt the movement of permeating gas or water vapor molecules and force the molecules to change their direction, resulting in longer permeation path followed. Layered silicates are more capable of reducing permeation through the film since their aspect ratio (length to thickness ratio) is very high compared to conventional fillers. At this point, effective aspect ratio must be considered for interpretation of permeability in nanocomposites since agglomeration of layered silicate platelets reduces the effective aspect ratio and length of the path must be traveled by the permeant. Generally a critical limit of layered silicate content is reported by many authors, due to the poorer exfoliation of nanofillers result in decreased efficiency of barrier improvement (Petersson and Oksman, 2006; Tunc et al., 2007; Luecha et al., 2010). In this study, the increase in the permeability of CLO10A-7.5\% sample can be attributed to more intercalated nanocomposite structure. Conformably to XRD and FTIR results, the marginal effectiveness of nanoclays at Cloisite 10A content of $7.5 \mathrm{wt} . \%$ is reduced compared to the $5 \mathrm{wt}$ \% sample. Due to more intercalated nanocomposite structure in the CZNC coating layer, the permeability of CLO10A$7.5 \%$ sample is very close to that of CLO10A-3\% samples although the layered silicate content was doubled.

\subsubsection{Water vapor barrier properties}

Biopolymer coatings can also be used to improve water vapor barrier of conventional polymeric films. Recently, Tihminlioglu et al. (2010) reported important decreases in WVP of films coated with a thin layer of corn zein. Corn zein layers coated on PP base films also showed better barrier to water vapor in our study. Water 


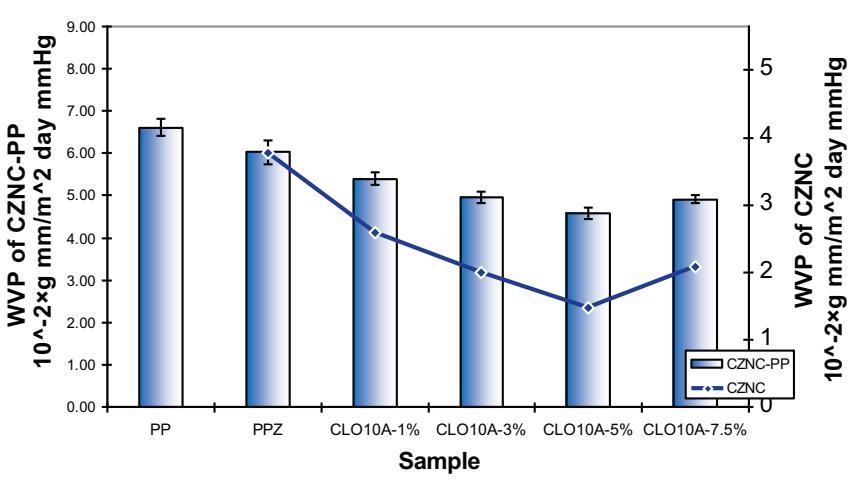

Fig. 5. Water vapor permeability (WVP) values of CZNC-PP films (in columns - left $y$-axis) and single CZNC layers (curve - right $y$-axis).

\section{Table 3}

Water vapor permeability (WVP) values of CZNC-PP films prepared by OMMT in corn zein coating layer.

\begin{tabular}{lll}
\hline Sample code & $\begin{array}{l}\text { WVP of CZNC-PP films } \\
\left({ }^{*} 10^{-2} \mathrm{~g} \mathrm{~mm} / \mathrm{m}^{2} \text { day } \mathrm{mmHg}\right)\end{array}$ & $\begin{array}{l}\text { WVP of CZNC layers } \\
\left({ }^{*} 10^{-2} \mathrm{~g} \mathrm{~mm} /\right. \\
\left.\mathrm{m}^{2} \text { day } \mathrm{mmHg}\right)\end{array}$ \\
\hline PPZ & $6.02 \pm 0.29$ & 3.78 \\
CLO10A-1\% & $5.39 \pm 0.15$ & 2.58 \\
CLO10A-3\% & $4.96 \pm 0.14$ & 1.99 \\
CLO10A-5\% & $4.57 \pm 0.14$ & 1.48 \\
\hline
\end{tabular}

vapor permeability changes caused by nanocomposite corn zein layers coated on PP films were presented in Fig. 5. Compared to intense effect of CZNC coatings on oxygen permeability of films, water vapor barrier improvements were less significant. Definitely, this is due to the high WVP of the corn zein. While oxygen permeability of corn zein was evaluated to be 12 times smaller than PP, WVP analysis showed that PP and pristine corn zein layer had similar water vapor permeability, $6.62 \times 10^{-2} \mathrm{~g} \mathrm{~mm} / \mathrm{m}^{2}$ day $\mathrm{mmHg}$ for $\mathrm{PP}$ and $3.78 \times 10^{-2} \mathrm{~g} \mathrm{~mm} / \mathrm{m}^{2}$ day $\mathrm{mmHg}$ for corn zein (Table 3 ). Nanocomposites coatings on PP also showed further improvement as well, decreasing the WVP of CZNC-PP up to 69\% for CLO10A-5\% sample as tabulated in Table 3).

WVP values of single CZNC layers were evaluated from the multilayer model (Eq. (2)) using the measured thicknesses, and plotted in Fig. 5. Comparably to the oxygen permeability plot, WVP of nanocomposite coating layers also showed distinctive decrease by increasing clay content. A continuous decrease by $60 \%$ in the WVP of single corn zein layer was achieved at 5 wt.\% clay loading denoted by CLO10A-5\%. Ability of layered silicates to improve water vapor barrier of synthetic and biopolymers were reviewed by many authors in the literature (Alexandre and Dubois, 2000; Ray and Bousmina, 2005; Paul and Robeson, 2008). Several studies reported improved barrier to water vapor for plant based biopolymer nanocomposites prepared by montmorillonite and other layered silicates (Tunc et al., 2007; Tang et al., 2008; Bae et al., 2009). Again for CLO10A-7.5\% an increase in WVP was observed similar to the oxygen permeability results that could be attributed to more intercalated structure of corn zein nanocomposites rather than exfoliated one. Layered silicates; when effectively distributed in the polymer matrix, creates impermeable obstacles to permeating water vapor molecules. Because of this, the effective path that a permeating water molecule must travel increases and the water vapor permeability decreases.

\subsubsection{Evaluation of nanocomposite performance on oxygen and water} vapor barrier of single CZNC layers

The effect of organomodified nanoclay content on WVP appeared to be analogous with the oxygen permeability of CZNC layers. Similar decrease trends in oxygen and water vapor permeability data can be followed for CZNC coating layers (Figs. 4 and 5) Depending on the degree of layered silicate nanoclay delamination in the polymer matrix, oxygen and water vapor permeability decreases due to more tortuous path required to be traveled by the permeant molecules.

Decreases in oxygen and water vapor permeability can also be explained by the employment of permeability models to coated corn zein nanocomposite layers.

Several permeability models were developed to understand the effect of fillers on the permeability of molecules in composite structures (Nielsen, 1967; Bharadwaj, 2001; and Lape et al., 2004). Permeability models differ in their assumptions and considered filler geometry. Models based on rectangular flakes can be applied to layered silicate nanocomposite systems. Although models were proposed for conventional composites, tortuosity effect of conventional fillers and nanofillers are similar since both are assumed to increase the permeation path in a similar manner (Sun et al., 2008; Choudalakis and Gotsis, 2009). Permeability models applied to prepared CZNC layers and their basic assumptions were tabulated in Table 4 . In the given equations, $\alpha$ and $\phi$ are the aspect ratio and volume fraction of clay platelets in the nanocomposites, respectively. $P$ and $P_{0}$ denotes for the permeabilities of pristine and nanocomposite polymer. $S$ in the Bharadwaj equation is the geometric factor included.

Permeability models employed to predict the aspect ratio in prepared corn zein nanocomposite layers fitted to experimental data are shown in Fig. 6 for oxygen and water vapor permeation through coated CZNC layers, respectively. The volume fractions of layered silicate in nanocomposites $(\phi)$ were calculated by using the Eq. (4), where $\rho c, \rho p$ and Mc denote for density of nanoclays, density of corn zein polymer, and mass percentage of nanoclays in the polymer matrix, respectively.

$$
\phi=\frac{1}{1+(\rho c(1-M c) /(\rho p M c))}
$$

As seen in Fig. 6, Nielsen model and Bharadwaj model $(S=0$, random silicate platelet orientation included version of Nielsen model) gave the best fitting to oxygen and water vapor permeability data. Both models gave aspect ratios around 94 and 283, respectively. Bharadwaj model with $S=1$ gives the same aspect ratio with Nielsen model. $S=0$ case of Bharadwaj Equation generally results in higher aspect ratios for well exfoliated systems since it considers different orientations of silicates resulting in theoretically possible shorter paths for permeants while $S=1$ situation considers the longest path available for permeating molecules. Schematic representations of $S=1$ and $S=0$ cases were given in the Fig. 7. Regarding the fitted models, the effective aspect ratio in our nanocomposites was estimated in the range of 94-283, which is in good agreement with the reported aspect ratio range (10-1000) for layered silicates (Ray and Bousmina, 2005; Choudalakis and Gotsis, 2009).

High aspect ratio found for CZNC layers prepared by incorporation of organomodified Cloisite 10A nanoclays might be accepted as an indication of effective preparation of nanocomposites. On the other hand, it must be noticed that the applied models are only considering available area and/or effective path of permeating molecule. Enhanced interactions between clay-polymer matrix and crystallinity changes (although corn zein has amorphous structure) as well as permeant solubilities are not considered in these models.

\subsection{Contact angle measurements}

Initial contact angle measurements were conducted in order to observe the effect of Cloisite $10 \mathrm{~A}$ nanoclay content on corn zein nanocomposite coated polypropylene films. Contact angle is the 
Table 4

Models together with formulas and assumptions applied to experimental oxygen and water vapor permeability data of single CZNC layers.

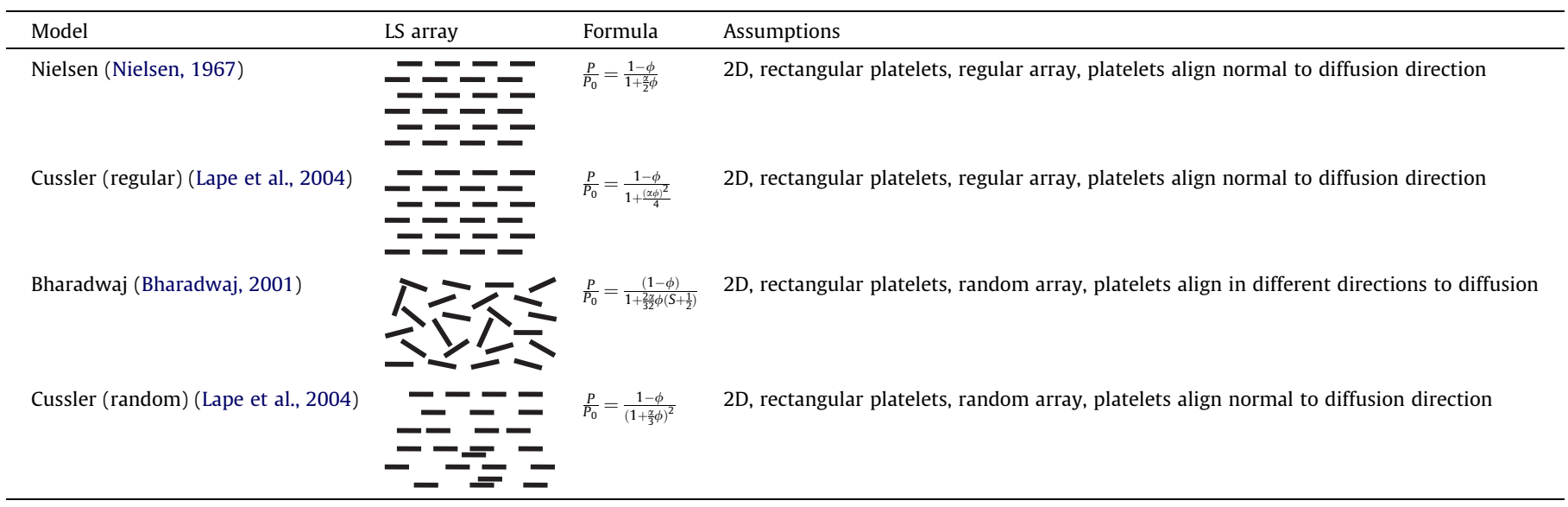

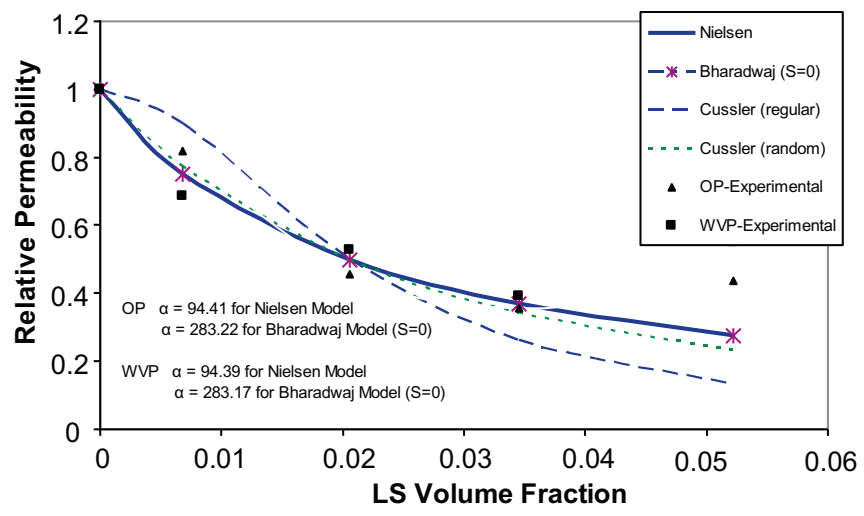

Fig. 6. Permeability models fitted to experimental oxygen and water vapor permeability data, aspect ratios found for best fitting models were also reported.

measure of hydrophobicity of a substance. As hydrophobicity of the surface decreases, water molecules tend to spread on surface more readily.

Measured water contact angles of the PP substrate and CZNC coated films were given in Table 5 . Values denoted by $\theta$ are the angle of tangent line to water drop with the surface. Zein coating reduced the contact angle of the film surface from $88.90^{\circ}$ to $54.25^{\circ}$, respectively due to more hydrophilic nature of corn zein. Measured contact angle value for zein coating is in good agreement with previously reported glycerol plasticized zein (Ghanbarzadeh et al., 2006; Tihminlioglu et al., 2010). OMMT used to prepare nanocomposites in this study increased hydrophobicity of CZNC coatings even in small concentrations. Increases in the hydrophobicity can be attributed to hydrophobic surface of montmorillonite after organomodification. Hydrophobicity of the added layered silicate determines the effect on contact angle of the polymer nanocomposite. Decreases in hydrophobicity of polymer surfaces were
Table 5

Initial contact angles measured for CZNC-PP samples.

\begin{tabular}{ll}
\hline Sample code & Avg. contact angle $(\theta)$ \\
\hline PP & $88.90 \pm 0.82$ \\
PPZ5 & $4.25 \pm 1.45$ \\
CLO10A-1\% & $56.06 \pm 1.02$ \\
CLO10A-3\% & $56.62 \pm 1.93$ \\
CLO10A-5\% & $61.13 \pm 0.89$ \\
CLO10A-7.5\% & $61.66 \pm 1.68$ \\
\hline
\end{tabular}

reported by the use of hydrophilic unmodified montmorillonite (Tunc et al., 2007) while hydrophobic organomodified montmorillonite was reported to increase hydrophobicity of the surface (Rhim et al., 2006).

Measured initial contact angles of the CZNC coatings were observed to be in good accordance with the water vapor permeability results. Several studies reported water vapor barrier improvements with more hydrophobic polymer surfaces (Polo et al., 1992; Bras et al., 2007; Hirvikorpi et al., 2011). The degree of surface hydrophobicity increased with increasing Cloisite 10A content. As degree of surface hydrophobicity increased, WVP of CZNC-PP films decreased indicating a possible relationship between contact angle changes and water vapor barrier due to presence of nanoclays in the polymer matrix. WVP of the coatings would be decreased by the presence of exfoliated nanoclays on the surface limiting water molecules to be absorbed by CZNC matrix and/or due to the decreased affinity of water molecules with more hydrophobic zein coating.

\section{Conclusion}

In this study, corn zein nanocomposite (CZNC) coatings on polypropylene (PP) films were prepared in order to develop a novel film system for food packaging applications. The study was focused on the investigation of oxygen and water vapor barrier of coated films due to organomodified montmorillonite (OMMT) delamination in

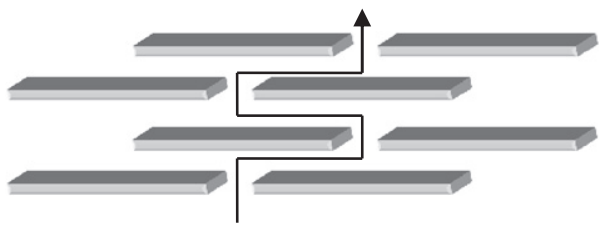

$S=1$

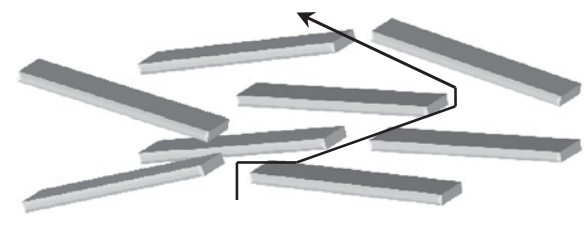

$S=0$

Fig. 7. $S=1$ (regular array, same with Nielsen model) and $S=0$ (random array) cases of Bharadwaj model. 
corn zein coatings. The final films showed good compatibility between CZNC coating and PP in terms of appearance and adhesion. CZNC coating with a thickness of only $5.9 \mu \mathrm{m}$, successfully improved the barrier properties of PP film. Coating decreased the oxygen permeability (OP) of prepared bilayer films to $25 \%$ of base PP film, while WVP decreased by $30 \%$ for the films prepared by 5 wt.\% Cloisite 10A nanoclay in the CZNC coating. The effect of nanocomposite structure on barrier of single corn zein layers were also investigated by using XRD and FTIR. Addition of $5 \mathrm{wt} . \%$ organomodified nanoclay showed to decrease OP and WVP of zein layers by $65 \%$ and $60 \%$, respectively due to more tortuous path formed by clay delamination. The level of intercalation/exfoliation was found to be influential on the barrier improvements. CZNC layers showed higher OP and WVP for $7.5 \mathrm{wt} . \%$ sample attributed to reduced delamination and may be some degree of agglomeration of organomodified nanoclay in nanocomposites. The barrier properties were also investigated theoretically by using various phenomenological permeability models. The effective aspect ratio in our nanocomposites was estimated in the range of 94-283, which is in good agreement with the reported aspect ratio range (101000) for layered silicates. In conclusion, excellent barrier properties of corn zein nanocomposites were successfully improved and combined with mechanically strong PP as a promising eco-friendly alternative to conventional barrier packaging systems.

\section{Acknowledgements}

Polinas Company and Southern Clay Products are acknowledged for providing polypropylene films and nanoclays used in the study. The authors also acknowledge IYTE Center for Materials Research and Professor Orhan Ozturk from IYTE Physics Department for their help in structural characterizations.

\section{References}

Alexandre, M., Dubois, P., 2000. Polymer-layered silicate nanocomposites: preparation, properties and uses of a new class of materials. Materials Science and Engineering 28, 1-63.

Bae, H.J., Park, H.I., Hong, S.I., Byun, Y.J., Darby, D.O., Kimmel, R.M., Whiteside, W.S., 2009. Effect of clay content, homogenization RPM, pH, and ultrasonication on mechanical and barrier properties of gelatin/montmorillonite nanocomposite films. Food Science and Technology 42, 1179-1186.

Bharadwaj, R.K., 2001. Modelling the barrier properties of polymer-layered silicate nanocomposites. Macromolecules 34, 9189-9192.

Bras, J., Vaca-Garcia, C., Borredon, M.E., Glasser, W., 2007. Oxygen and water vapor permeability of fully substituted long chain cellulose esters (LCCE). Cellulose 14, 367-374.

Cervantes-Uc, J.M., Cauich-Rodriquez, J.V., Vazques-Torres, H., Garfias-Mesias, L.F., Paul, D.R., 2007. Thermal degradation of commercially available organoclays studied by TGA-FTIR. Thermochimica Acta 457, 92-102.

Chen, P., Zhang, L., 2006. Interaction and properties of highly exfoliated soy protein/ montmorillonite nanocomposites. Biomacromolecules 7 (6), 1700-1706.

Chen, G., Liu, S., Chen, S., Qi, Z., 2001. FTIR spectra, thermal properties, and dispersibility of a polystyrene/montmorillonite nanocomposite. Macromolecular Chemistry and Physics 202, 1189-1193.

Cho, S.Y., Park, J.W., Rhee, C., 2002. Properties of laminated films from whey powder and sodium caseinate mixtures and zein layers. Lebensmittel-Wissenschaft und -Technologie 35, 135-139.

Choudalakis, G., Gotsis, A.D., 2009. Permeability of polymer/clay nanocomposites: a review. European Polymer Journal 45, 967-984.

Corradini, E., Mattoso, L.H.C., Guedes, C.G.F., Rosa, D.S., 2004. Mechanical, thermal and morphological properties of poly $(E$-caprolactone $) /$ zein blends. Polymers for Advanced Technologies 15, 340-345.

Cuq, B., Gontard, N., Guilbert, S., 1998. Proteins as agricultural polymers for packaging production. Cereal Chemistry 75, 1-9.

Cutter, C.N., 2006. Opportunities for bio-based packaging technologies to improve the quality and safety of fresh and further processed muscle foods. Meat Science $74,131-142$.

Gao, C., Stading, M., Wellner, N., Parker, M.L., Noel, T.R., Mills, E.N.C., Belton, P.S., 2006. Plasticization of a protein-based film by glycerol: a spectroscopic, mechanical and thermal study. Journal of Agricultural and Food Chemistry 54, 4611-4616.
Ghanbarzadeh, B., Oromiehi, A.R., 2008. Biodegradable biocomposite films based on whey protein and zein: barrier, mechanical properties and AFM analysis. International Journal of Biological Macromolecules 43, 209-215.

Ghanbarzadeh, B., Musavi, M., Oromiehie, A.R., Rezayi, K., Razmi, E., Milani, J., 2006. Investigation of water vapor permeability, hydrophobicity and morphology of zein films plasticized by polyols. Iranian Polymer Journal 15 (9), 691-700.

Gioia, L.D., Guilbert, S., 1999. Corn protein-based thermoplastic resins: effect of some polar and amphiphilic plasticizers. Journal of Agricultural Food Chemistry 47, 1254-1261.

Herald, T.J., Obuz, E., Twombly, W.W., Rausch, K.D., 2002. Tensile properties of extruded corn protein low-density polyethylene films. Cereal Chemistry 79 (2) 261-264.

Hernandez-Izquerdo, V.M., Krochta, J.M., 2008. Thermoplastic processing of proteins for film formation: a review. Journal of Food Science 73 (2), 30-39.

Herrera-Alonso, J.M., Marand, E., Little, J.C., Cox, S.S., 2009. Transport properties in polyurethane/clay nanocomposites as barrier materials: effect of processing conditions. Journal of Membrane Science 337, 208-214.

Hirvikorpi, T., Vaha-Nissi, M., Harlin, A., Salomaki, M., Areva, S., Korhonen, J.T. Karppinen, T., 2011. Enhanced water vapor barrier properties for biopolymer films by polyelectrolyte multilayer and atomic layer deposited $\mathrm{Al}_{2} \mathrm{O}_{3}$ doublecoating. Applied Surface Science 257, 9451-9454.

Hong, S.I., Krochta, J.M., 2003. Oxygen barrier properties of whey protein isolate coatings on polypropylene films. Journal of Food Science 68, 224-228.

Hong, S.I., Krochta, J.M., 2006. Oxygen barrier performance of whey-protein coated plastic films as affected by temperature, relative humidity, base film and protein type. Journal of Food Engineering 77, 739-745.

Ijdo, W.L., Kemnetz, S., Benderly, D., 2006. An infrared method to assess organoclay delamination and orientation in organoclay polymer nanocomposites. Polymer Engineering and Science 46, 1031-1039.

Johnston, C.T., Premachandra, G.S., 2001. Polarized ATR-FTIR study of smectite in aqueous suspension. Langmuir 17, 3712-3718.

Lange, J., Wyser, Y., 2003. Recent innovations in barrier technologies for plastic packaging - a review. Packaging Technology and Science 16, 149-158.

Lape, N.K., Nuxoll, E.E., Cussler, E.L., 2004. Polydisperse flakes in barrier films. Journal of Membrane Science 2004 (236), 29-37.

Lawton, J.W., 2002. Zein: a history of processing and use. Cereal Chemistry 79, 1-18.

Lawton, J.W., 2004. Plasticizers for zein: their effect on tensile properties and water absorption of zein films. Cereal Chemistry 81, 1-5.

Lee, J.W., Son, S.M., Hong, S.I., 2008. Characterization of protein-coated polypropylene films as a novel composite structure for active food packaging application. Journal of Food Engineering 86, 484-493.

Luecha, J., Sözer, N., Kokini, J.L., 2010. Synthesis and properties of corn zein/ montmorillonite nanocomposite films. Journal of Materials Science 45, 35293537.

Madejova, J., 2003. FTIR techniques in clay mineral studies vibrational spectroscopy 31, 1-10.

Marsh, K., Bugusu, B., 2007. Food packaging - roles, materials, and environmental issues. Journal of Food Science 72, 39-55.

Miller, K.S., Krochta, J.M., 1997. Oxygen and aroma barrier properties of edible films: a review. Trends in Food Science \& Technology 8, 228-237.

Nielsen, L.E., 1967. Models for the filled polymer system. J. Macromol. Sci. Chem. A1, 929-942.

Ozcalik, O., 2010. Master of Science Thesis in Material Science and Engineering, İzmir Institute of Technology.

Padua, G.W., Wang, Q., 2002. Formation and properties of corn zein films and coatings. In: Gennadios, A. (Ed.), Protein Based Films and Coatings. CRC Press, USA.

Paul, D.R., Robeson, L.M., 2008. Polymer nanotechnology: nanocomposites. Polymer 49, 3187-3204.

Pavlidou, S., Papaspyrides, C.D., 2008. A review on polymer-layered silicate nanocomposites. Progress in Polymer Science 33, 1119-1198.

Petersson, L., Oksman, K., 2006. Biopolymer based nanocomposites: comparing layered silicates and microcrystalline cellulose as nanoreinforcement. Composites Science and Technology 66, 2187-2196.

Polo, M.M., Mauguin, C., Voilley, A., 1992. Hydrophobic films and their efficiency against moisture transfer. 1 . Influence of the film preparation technique. Journal of Agricultural Food Chemistry 40, 407-412.

Ray, S.S., Bousmina, M., 2005. Biodegradable Polymers and Their Layered Silicate Nanocomposites: In Greening The 21st Century Materials World. Progress in Materials Science 50, 962-1079.

Ray, S.S., Bousmina, M., 2008. Polymer nanocomposites and their applications. American Scientific Publications, CA, USA.

Rhim, J.W., Lee, J.H., Hong, S.I., 2006. Water resistance and mechanical properties of biopolymer (alginate and soy protein) coated paperboards. LWT - Food Science and Technology 39, 806-813.

Ryu, S.Y., Rhim, J.W., Roh, H.J., Kim, S.S., 2002. Preparation and physical properties of zein-coated-high amylose corn starch film. Lebensmittel-Wissenschaft und Technologie 35, 680-686.

Shukla, R., Cheryan, M., 2001. Zein: the industrial protein from corn. Industrial Crops and Products 13, 171-192.

Sun, L., Boo, W.J., Clearfield, A., Sue, H.J., Pham, H.Q., 2008. Barrier properties of model epoxy nanocomposites. Journal of Membrane Science 318, 128-136.

Tang, X., Alavi, S., Herald, T.J., 2008. Barrier and mechanical properties of starchclay nanocomposite films. Cereal Chemistry 85, 433-438. 
Tharanathan, R.N., 2003. Biodegradable films and composite coatings: past, present and future. Trends in Food Science \& Technology 14, 71-78.

Tihminlioglu, F., Atik, I.D., Özen, B., 2010. Water vapor and oxygen-barrier performance of corn-zein coated polypropylene films. Journal of Food Engineering 96, 342-347.

Tihminlioglu, F., Atik, İ.D., Özen, B., 2011. Effect of corn-zein coating on the mechanical properties of polypropylene packaging films. Journal of Applied Polymer Science 119, 235-241.

Tunc, S., Angellier, H., Cahyana, Y., Chalier, P., Gontard, N., Gastaldi, E., 2007. Functional properties of wheat gluten/montmorillonite nanocomposite films processed by casting. Journal of Membrane Science 289, 159-168.
Weller, C.L., Gennadios, A., Saraiva, R.A., 1998. Edible bilayer films from zein and grain sorghum wax or carnauba wax. Lebensmittel-Wissenschaft und Technologie 31, 279-285.

Wu, Q., Yoshino, T., Sakabe, H., Zhang, H., Isobe, S., 2003. Chemical modification of zein by bifunctional polycaprolactone (PCL). Polymer 44, 3019-3909.

Yu, J., Cui, G., Wei, M., Huang, J., 2007. Facile exfoliation of rectorite nanoplatelets in soy protein matrix and reinforced bionanocomposites thereof. Journal of Applied Polymer Science 104, 3367-3377. 